\title{
The Problematics of Scientific Discovery
}

\author{
Sudhakar Venukapalli
}

\section{ABSTRACT}

Historically, the problem of discovery or the problem of the genesis of scientific ideas has been taken seriously by the historians, psychologists, sociologists and philosophers who analyzed the creative thinking and formation of ideas and attempted to provide a meaningful account of them. In fact, the philosophical concern with scientific discovery is as old as science and philosophy of science themselves. However, almost throughout the first half of 20th century, philosophical reflection on the phenomenon of scientific discovery remained in a state of suspended animation. This is because the dominant trend in philosophy of science in this period outlawed it. The dominant view in philosophy of science maintained that the phenomenon of scientific discovery is philosophically irrelevant, and an adequate philosophical understanding of science should confine itself to the way in which scientific theories are justified; it was assumed that the process of justification is a neat, spick-and-span phenomenon eminently suited to be described in terms which are, logically speaking, cut and dry. The process of justification or evaluation according to this orthodox view constitutes the essence of science. Obviously, justification was demarcated from discovery. Justification, because of its supposed epistemic transparency, became the exclusive focus of philosophical attention to the detriment of discovery. The invidious distinction between discovery of scientific ideas and justification of finished ideas of science remained the catchword for a long time. This paper is an attempt to critically examine the nihilistic attitude of the dominant philosophies of science and to arrive at a philosophical theory of scientific discovery.

Keywords: divorce, marriage, value, spirituality.

Published Online: June 16, 2021

ISSN: $2736-5514$

DOI: $10.24018 /$ theology.2021.1.3.15

Sudhakar Venukapalli

The English and Foreign Languages University, Hyderabad, India. (e-mail:

sudhakarvenu.efluniversity@gmail.com)

\section{INTRODUCTION}

Where do scientific ideas come from? When does a scientific discovery occur? How are scientific theories generated? Why does a particular idea and not another occur to the scientist? Is the process of conceiving a new idea amenable to a rational investigation? These are some of the fascinating and seminal issues in the contemporary philosophy of science and methodology of scientific research [1]-[5]. The problem of scientific discovery can be explicated in terms of three issues keeping in mind the past and the present discussions, namely:

1) Is scientific discovery philosophically relevant?

2) If scientific discovery is philosophically relevant then what should be its adequate construal?

3) What bearing does such a construal have on our idea of science as a cognitive activity?

It may be noted that the question whether philosophy of science should concern itself with discovery cannot be decided by a stipulated definition of discovery and/or a conventional delineation of the domains of various disciplines which study science. It is a substantial question with implications for our ideas about the nature of science as well as our ideas of philosophical understanding of science [6]-[9].
To the question, 'Is scientific discovery philosophically relevant?' the standard answer has been, 'NO'. Obviously, the answer presumes a certain conception of discovery, which implies its philosophical irrelevance, and this conception of discovery is rooted in a certain conception of science and philosophy of science [10], [11]. Therefore, those who want to say 'Yes' to the above question must show that the opposite view entertains a narrow conception of discovery and that a broad conception of discovery might not imply the philosophical irrelevance of discovery. Hence the discussion on the first issue concerns a critical evaluation of the idea of discovery, which results in the denial of the philosophical concern about discovery. If such an idea of discovery is untenable, what, then, is an adequate construal of discovery and how should we recast our approach so that we can arrive at it and work out its details? This takes us to the second issue, which therefore comprises the following questions:

Is the delineation of context of discovery as an autonomous entity exemplifying a distinct phase of scientific inquiry tenable? In other words, should we accept the mutual exclusivity and collective exhaustively of discovery justification distinction? If the denial of philosophical relevance of discovery is based upon a narrow conception of discovery what then is its broad construal and how do we ensure that the holistic conception of discovery does not suffer from looseness? That is to say, how can we arrive at a 
formulation of 'discovery' so as to characterize it in terms of a broad spectrum such that in our account of discovery we take into consideration what precedes discovery in the narrow sense and also what succeeds it with the result we undo discovery-justification dichotomy. These questions are very important since the view that discovery is philosophically irrelevant is based upon the acceptance of discoveryjustification dichotomy. Perhaps, with such a broadened notion of discovery philosophical theory of discovery might be a methodology of discovery rather than logic of discovery in however loose a sense of 'logic'.

The third issue concerns, among other things, the problem of scientific rationality on the one hand and on the other, the overall character of the structure and dynamics of scientific knowledge that are best construed in evolutionary and dialectical terms. These are some of the central issues that are discussed in this paper under the rubric of the problem of discovery.

In the first half of 20th century, philosophical reflection on the phenomenon of scientific discovery remained in a state of suspended animation. This is because the dominant trend in philosophy of science in this period outlawed it. The dominant view in philosophy of science maintained that the phenomenon of scientific discovery is philosophically irrelevant and an adequate philosophical understanding of science should confine itself to the way in which scientific theories are justified; it was assumed that the process of justification is a neat, spick-and-span phenomenon eminently suited to be described in terms which are, logically speaking, cut and dry. The process of justification or evaluation according to this orthodox view constitutes the essence of science. Obviously, justification was demarcated from discovery. Justification, because of its supposed epistemic transparency, became the exclusive focus of philosophical attention to the detriment of discovery. The invidious distinction between discovery of scientific ideas and justification of finished ideas of science remained the catchword for a long time.

\section{DECONSTRUCTING NIHILISM IN SCIENTIFIC DISCOVERY}

Apart from the unquestioned philosophical superiority of justification-process over discovery-process in terms of the rational character of the former, which makes it amenable to logical articulation, several other reasons for a nihilistic attitude towards discovery-process were also put forward. A few of these arguments are presented below.

1) Scientific discovery was considered to be a psychological and hence a subjective phenomenon.

2) The absence of any logical method of arriving at new knowledge was held against any attempt to treat discovery as a philosophical problem.

3) The phenomenon of discovery was considered to be an absolutely creative process not amenable to rational analysis and the process of justification is a non-creative process.

4) It was felt that since we cannot predict what discoveries are in store for us in future, an explanatory theory of discovery is impossible or at least useless.

5) A philosophical theory of discovery, if at all possible, must explain discovery in the sense prescribed by deductivenomological model; since that possibility is nil, any endeavor to arrive at a philosophical explanation of discovery is totally uncalled for, and finally

6) If a theory of discovery is possible, then we must be able to make all discoveries immediately and this is inconceivable.

All these arguments, which are mostly repetitive, are critically analyzed below.

\section{A. Subjectivity Vs. Objectivity in Scientific Discovery}

First of all, 'discovery' need not denote only a psychological phenomenon. It might also concern what may be called discovery-generating-situation, which is an objective phenomenon [12]. The discovery-generating situation might comprise a problem-solution context in which the scientific community finds itself, the constraints that it imposes on itself in dealing with the problem, the way in which it locates that situation in relation to the past and the future of the discipline, etc. Hence, even while acknowledging the subjective or psychological dimension of discovery one can make room for an objective dimension of discovery process.

\section{B. Logic of Scientific Discovery}

Secondly, even if one agrees that there is no logical method of arriving at new knowledge one need not deny that there are logical relations between old knowledge and new knowledge which play a role, in the generation of the latter and these relations can be characterized in logical or, at least, quasilogical terms [12].

\section{Creativity in Discovery and Justification}

Thirdly, the fact that discovery is a creative process in no way supports the thesis that philosophy of science should confine itself to the context of justification. For, this wrongly assumes that the process of justification is a non-creative process. Justification also is highly challenging and therefore a creative task. Though many a time justification or corroboration or confirmation is a routine and mechanical task, there are many occasions when justification has demanded ingenuity and many achievements at justification are as much rewarding and rewarded as discovery.

\section{Predictability/Explanatory Value of Theory of Scientific Discovery}

Fourthly, the argument that a philosophical theory of discovery is impossible or at least useless because discoveries are unpredictable assumes the validity of the structuralidentity thesis, which has been called into question in recent times. First of all, all sciences are not equal in terms of the predictive abilities of their theories. Physical science in general, and physics in particular, has achieved perfection in this direction. Even here theories of microphysics very much lag behind the theories of macrophysics. Many of the fundamental theories of biology are far from achieving perfection in connection with their predictive ability [13]. The case of the social and behavioral sciences is even worse. But we cannot say that the explanatory value or the power of these sciences is very much less than that of physics. Their claim to have shed light on their respective domain cannot be challenged on the grounds of their far-from-perfect capacity for prediction. The very rationale behind the demand that an explanation must be predictive has been questioned radically. If by prediction we mean something other than the mere 
fulfillment of the trivial requirement that the explanans have a yet unobserved instances, then what are involved in prediction are new observation predicates and hence, in terms of the deductive view, additional set of correspondence rules. As Mary Hesse [14] has convincingly shown, there is no rational method of adding to the corresponding rules on the pure deductive view and hence, the cases of prediction, in any substantial sense cannot be rationally accounted for on the deductive view. A philosophical theory of discovery, therefore, may not have predictive value though it might explain the phenomenon of discovery by brining to surface the mechanisms that underlie the process of scientific innovation.

\section{E. Logicality, Deductivity and Rationality in Scientific Discovery}

The unsatisfiable demand that a philosophical theory of discovery should be deductive in character is itself questionable. Those who make this demand do so because of their commitment to the deductive-nomological model of explanation. The illegitimacy of this demand needs some explanation. It is assumed here that the deductive explanation is an ideal explanation. The dominant tradition in the theory of explanation till now has equated rationality with logicality and logicality with deductivity and thus rationality with deductivity. The rationale behind this equation is the idea that all ideal knowledge is deductive, a belief that can be trace to Plato himself. It may be also noted that not only rationalists but also empiricists were deductivists. Speaking of Hume, Antony Flew [15] rightly observes:

"In his account of arguing from experience Hume implicitly presupposes an exclusively deductive ideal of reason. He first sets upon incomplete syllogism as displaying the form of al arguments from experience. Then he shows that there is no satisfactory way of establishing the missing premise. From this he proceeds to argue that reason and "understanding has no past in the operations" (Enquiry, Section V) and then to seek out and examine the principle of human nature which gives this "mighty authority to experience" (Enquiry, Section IV). In all this he is being incongruously Cartesian"

In philosophy of science the obsession with the deductive ideal is all the more transparent. For the Inductivists the ideal of reason implicit in the structure of inference required to justify knowledge-claims is deductive. Of course, inductivism accepts the deductive ideal in an elliptical form. This is evident in the attempts of traditional inductivists like J. S. Mill [16] to develop an inductive logic supposedly approximating deductive logic in kind if not in degree.

My intention in going into the above historical details was only to underscore the point that the demand that a philosophical theory of discovery must be deductive in character as well as consequent contention that such a theory is impossible is grounded in a dogma which has no logical grounds but only historical roots. The validity of this dogma has throughout been assumed and its hold is so strong that it has never been called into question. The above objection against the possibility of a philosophical theory of discovery has a purchasing value only if the age-old dogma is left unquestioned.
However, the deductivist view maintains that there cannot be a philosophical explanation of scientific discoveries. An explanation of discovery should confine itself to the questions concerning the occurrence and non-occurrence of certain discoveries. Such an explanation is a historical explanation, and they are deductive explanations. But they are not philosophical explanations because they involve reference to non-intellectual factors. A philosophical explanation of discoveries must confine itself to intellectual factors and like any adequate explanation it must be deductive in form and that is impossibility.

The whole argument is questionable because it is essentially defective. First of all, it is wrong to say that historical explanations are deductive in form, even when they are; their explanatory value is either trivial or questionable. Even if a historian invokes laws and deduces certain statements describing the historical phenomenon to be explained, the invocation of those laws is not essential to the explanatory character of the historical narrative. As Kuhn [17] points out "however much laws may add substance to an historical narrative, they are not essential to its explanatory force. That is carried, in the first instance, by the facts the historian presents and the manner in which he juxtaposes them".

Secondly, it is absolutely doubtful that all scientific explanations are deductive-nomological in character. Deductive nomologists have failed to reduce non-deductive explanations to deductive ones even approximately. With this failure the claim that non-deductive explanations in science have only a provisional significance becomes spurious. If there is no basis to say that all-scientific explanations are deductive in character, it is illegitimate to demand a philosophical explanation to be deductive in character. Thirdly, even if scientific explanations are deductive, it does not justify the demand that a philosophical theory be deductive in character unless one accepts the dogma that equates rationality with logicality and logically with deductivity. Fourthly and most importantly, as Mary Hesse [18] points out, the Deductive-nomoogical model is incompatible with the basic fact about scientific explanation, namely, that a scientific explanation essentially involves a redescription of the domain of the explicandum. The contemporary discussions about explanation have put the prevailing notion of explanation on the defensive and they have come out with a new construal of explanation wherein the ideas of reasons and intelligibility have replaced the ideas of causes and deductivity.

\section{F. Antireductionist Explanatory Theory of Scientific Discovery}

Equally indefensible is the last objection against the possibility of a theory of discovery according to which the possibility of a theory of discovery has the inconceivable implication that all discoveries can be made immediately following the realization of such a theory. This objection naively construes an explanatory theory of discovery as a set of thumb-rules for making discoveries. But those who attempt to provide an explanatory theory of discovery aim at a rich understanding of the complex texture of the cognitive act. The demand on a theory of discovery that it should provide thumb-rules for discovery and must really engender some is 
as absurd as demanding from the reductionists that they must produce life out of the physical and chemical components to which the reductionists reduce life as a biological phenomenon. Even if the reductionist claim is not accepted it is not because reductionists have failed to produce life out of physico-chemical elements, but because reductionism fails to account for a variety of biological practices and problemsolution situations as well as the questionable epistemological presuppositions and consequences of the reductionist thesis. Hence the possibility of a logic of discovery and/or the legitimacy of an explanatory theory of discovery-process should be viewed in terms of the light it sheds on the nature of scientific activity as a whole and its doing justice to a variety of problem-solution situations as well as the tenability of its epistemological pre-suppositions and consequences. Needless to say, the demand for immediate practical consequences from a philosophical theory of discovery is based on a naive view of the relation between philosophy of science and scientific practice. The utility of a theory of discovery must be decided on the question whether it can illuminate or clarify some important philosophical problems about the nature of science.

The problem of discovery, as mentioned above, was kept under a state of suspended animation for more than half a century and was revived generating the cliche that the problem of discovery has been rediscovered. This rebirth was not only due to the realization of the indefensibility of the various arguments put forward against the possibility of a philosophical theory of discovery but also due to certain developments of seminal importance in philosophy of science which have altered our conception of science, its method, aim, dynamics and rationale. A few words about them are in order.

\section{PRoblematics of CONTEXT OF JUSTIFICATION}

As I have mentioned already, the major plank of the attack on the view that maintains the possibility of a philosophical theory of discovery is the invidious distinction between discovery and justification. Reichenbach was taken to be not only as advocating the invidious distinction between the context of discovery and the context of justification but also as one of those who introduced this distinction itself. This is the conventional interpretation of Reichenbach. As against this, philosophers like Martin Curd [19] maintain that Reichenbach's original distinction was quite different in nature and in application from the one usually attributed to him. However, the conventional view finds its justification in the following words of Reichenbach [20], "The philosopher of science is not much interested in thought processes which lead to scientific discoveries.... That is, he is interested not in the context of discovery but in the context of justification". However, Reichenbach's distinction between context of justification and context of discovery is related to his distinction between the descriptive and normative tasks of epistemology. Reichenbach makes a distinction between Psychology of discovery and descriptive epistemology as it figures in the context of discovery. According to him while psychology is interested in the actual process of thinking, descriptive epistemology aims "to construct thinking processes in a way in which they ought to occur if they are to be ranged in a consistent system; or to construct justifiable sets of operations which can be intercalated between the starting-point and the issue of thought processes, replacing the real intermediate links. (Descriptive) Epistemology thus considers a logical substitute rather than real processes" [20]. In other words, descriptive epistemology seeks to provide rational reconstruction and not merely photographic representation of knowledge. The rational reconstruction corresponds ideally to the form in which the thinking occurs. It is the form in which thinking processes are communicated to other persons rather than the form in which it is subjectively performed. Hence descriptive epistemology is also normative in its orientation though the sense in which it is normative is weaker than the one in which critical epistemology is. As distinct from descriptive epistemology, critical epistemology attempts to uncover, articulate, and systematize the norms which ought to be satisfied by a knowledge claim in order to be valid or acceptable.

Now, it is perfectly acceptable if Reichenbach means that a descriptive account of discovery cannot be a task of philosophy of science. It is also acceptable that in order for the discovery to be worthwhile object of philosophy of science the notions of norms and constraints are to be highlighted by a rational reconstruction. It then becomes clear that Reichenbach's distinction between the context of discovery and the context of justification should not be taken to mean as supporting the claim that philosophy of science should confine itself to the context of justification. And therefore, it is wrong to push him into the camp of antidiscovery philosophers. That is to say, though Reichenbach made a distinction between context of discovery and context of justification, the distinction is not used as a plank to establish that philosophy of science should confine itself to justification. For philosophy of science as epistemology of science, in Reichanbach's eyes, also deals with discovery though, as epistemology ought to, in terms of its rational reconstruction rather than a photographic representation. But at the same time his somewhat confusing assertion that the descriptive task of epistemology "forms a part of sociology" [20] seeks to identify epistemology of discovery with the sociology of discovery with the result the problem of discovery gets pushed beyond the pale of epistemology proper, that is, epistemology as a normative inquiry. Hence Reichenbach's epistemological construal of discovery swings like a pendulum and lacks stability, a fact that explains why he is pushed into the camp of the enemies of discovery. In his later writings Reichenbach justifies the nihilistic characterization of his approach to the problem of discovery where he says, for example, "The act of discovery escapes logical analysis;... it is not the logician's task to account for scientific discoveries; all he can do is to analyze the relation between given facts and a theory presented to him with the claim that it explains these facts. In other words, logic is concerned only with the context of justification" (1958).

To recapitulate, it was thought that the context of discovery was an opaque area with a lot of problems amenable to the type of explication and articulation accepted by philosophers of science which was not so, it was thought, in the case of the context if justification. Whatever be the nature of the evaluative process and however different its descriptions are, i.e., irrespective of the controversy over the nature of the 
justification process, it was commonly accepted that the context of justification itself is a transparent domain whose transparence and smoothness lend science its rationality. It is this, which tilted the balance totally in favor of the context of justification.

But soon it was realized that the picture of justification was not as rosy as it was thought. Popper failed to provide objective norms, which could tell us when the dogmatic retention of a hypothesis in the face of its falsification ceases to be "healthy"-a fact, which undermines falsifiability notion of evaluation vis-a-vis the verifiability conception. The former was supposed to be philosophically superior because of its logical asymmetry with the latter, which has been haunted by Hume's ghost.

Karl Popper [21] had recognized the seminal importance of problems in the structure of scientific thought, but he failed to fully work out the rich texture of the scientific problematic. However, he rightly recognized science as essentially a problem-solving activity and humans as problem-solving animals. This is because for Popper the recognition of the centrality of the problem was important only to the extent that such a recognition replaces 'data' as the beginning of scientific thinking - an idea that was central to inductivism. In other words, in Popper's scheme the problem stands in the beginning but it only any epistemological dynamics [22].

For Thomas Nickles on the other hand,the ideas of problems and science as a problem-solving activity are basic in the scientific problematic. Central to Nickles' idea of problems is his notion of "constraints" as constitutive of problems. According to him, Problem $=$ constraints + demand. The solution lies in the direction pointed to by the constraints. The direction may be sometimes straightforward when the constraints imply logically or deductively a solution or may be sometimes round about. Note that it needs reasoning to go from constraints to solution. Also, the perception of a problem involves the grasping of the constraints and understanding the demand made under those constraints - a perfectly rational process. It may also be noted that the constraints may not be given at one go. The progressive formulation of constraints is the progressive articulation of a problem which is how a problem grows. The perception of a problem, the developing of a problem and arriving at a permissible solution are all fully rational exercises that precede the stage of the so-called rational evaluation of solution. That is to say, generation involves perception of a problem and some kind of selection for preliminary evaluation and therefore the terms of its articulation are to a great extent normative. It is because of this normativity that problems and constraints constitute two faces of the same kind such that the distinction between them is possible only in the abstract and not in the actual scientific practice. The inseparability of problems from constraints makes the structure of a problem rich and complex lending it "crucial importance to the methodology of discovery" [23]. The idea that discovery is illegitimate as a philosophical topic is the result of the neglect of "problem" as a methodological category. The result of this neglect, Nickles believes, "is a theory-oriented bias in philosophy of science, but one which can be corrected by a more problem-oriented approach" [23].

The consequence of the denial of the cognitive relation between discovery and evaluation was that the initial probability of a hypothesis was condemned to be zero such that no amount of positive evidence could be considered contributing towards the probability of a hypothesis. This is amazingly counter-intuitive. Thomas Kuhn showed that the evaluation of the theories is to be basically characterized in sociological terms such that if there is no such thing as logic of discovery, equally there is no such thing as logic of justification. The philosophical revival of discovery to a great extent is the result of these developments which have put the context of justification on the defensive and showed that the justification process is not only problematic but is no less vulnerable. This is the result of the historical-orientation which philosophy of science has undergone.

As Thomas Nickles [23] points out

"interest in historical cases was fired by the writings of Thomas Kuhn and by the debate among Kuhn, Popper, Imre Lakatos and Paul Feyerabend over the implications of history of science for philosophy of science. One of the implications on which all agreed was that scientific confirmation or corroboration is not the neat logical process, which the classical positives and Popperians had taken it to be. There is no infallible logic of testing and justification in the sense of a simple set of logical rules for the acceptance and rejection of theories. This breakdown in traditional logics of justificationparadigmatic contributions to the 'logic' of science - no doubt weakened the invidious distinction drawn between justification and discovery and helped to make discovery a more respectable topic for philosophers"

According to Richard M. Burian [24], like discovery, justification is also highly context-dependent, and he says,

"....our standards of justification and support are not wholly independent of background information, of empirical assumption and presuppositions, of relativity to interests and purposes. This is not just the Bayesian or Popperian point that we must take background information and temporal order into account in evaluating hypotheses. It is the more radical point that the criteria and standards of rationality change substantially as we learn about the World and that the justification for these changes' rests, at least in part, on substantive knowledge of the World. In short, like discovery, epistemic evaluation of the claims of science is contextually bound and, because of this, cannot be properly treated as if it were wholly a temporal..."

One can sum up these developments that contributed towards the revival of the problem of discovery by saying that the sole reason for the latter is slow but systematic breakdown of the positivist tradition in philosophy of science.

\section{THE FAILURE OF POSITIVISM AND ITS LOGICAL RECONSTRUCTION PROGRAMME}

Positivism in philosophy of science specified the task of philosophy of science as the logical reconstruction of scientific knowledge. The logical reconstruction programme that was envisaged aimed at laying bare the deductive structure of scientific explanations, supposedly common to all scientific theories irrespective of the differences in content, on the one hand and explicating scientific knowledge in terms of a theoretical super-structure and observational sub-structure in the other such that the former was considered to be related to the latter in quasi-deductive ways. It is to be 
noted that both these aspects of the logical reconstruction programme looked upon finished scientific theories as constructing the essence of scientific activity, such that the product as distinguished from the process was exclusively treated as the essence of scientific activity. Consequently "discovery" which is related to what goes before the product was treated as lying beyond the legitimate domain of philosophy of science. But the logical reconstructionist programme itself failed. The so-called subject independent and context-free structure of all scientific theories, whose explication was aimed at, itself proved to be a pure invention. Further, neither were the candidates for playing the role of indubitable basics constituting the observational substructure available, nor was it possible to work out the quasi-deductive ways in which the two components of the architectural picture of science were related. The breakdown of the programme led to the breakdown of the exclusive privilege of product over process.

Positivism suffered another setback with the collapse of the equations, which it laid between rationality and logicality, and between logicality and deductivity. The new theory of rationality in general and scientific rationality in particular totally undid the positivist theory of rationality and replaced it by a view which construes rationality not in terms of certain fixed basic principles, but in terms of our ability to alter our belief systems adaptively in the face of changing circumstances. In other words, the idea of rationality gets its location within the scheme of thought-praxis nexuses and is construed in evolutionary terms.

\section{TOWARDS A PHILOSOPHICAL THEORY OF SCIENTIFIC DISCOVERY}

In what follows, I discuss the main contours of the orientation of an adequate theory of scientific discovery in terms of what it should not do and what it should do. However indefensible the arguments against the possibility of a theory of discovery are, they definitely have some lesson concerning what an adequate theory of discovery ought not try to be. Such an attempt must also be guided by our awareness of the pitfalls into which some attempts at a philosophical theory of discovery fell.

First of all, a philosophical theory of discovery should not even bother about the question whether discovery is relevant or not. It should simply try to address the question: "what should be an adequate philosophy of discovery?" Such an apparently highbrow step is necessitated by the fact that any attempt to establish the philosophical relevance of discovery is liable to be browbeaten because of the prevailing notions of scientific rationality.

It must be borne in mind that the philosophical relevance of discovery can be established only on the basis of an alternative conception of rationality. Such conception of rationality can emanate only from an account of science, which highlights those dimensions of scientific activity suppressed by traditional account and the prevailing notion of scientific rationality. Those dimensions can be highlighted provided the problem of discovery is grappled within philosophical categories. Thus, the philosophical relevance of discovery can be established only upon actually working out a theory of discovery. This might appear ironical but such an irony characterizes any inquiry, scientific or philosophical. Further, it must be noted that the rejection of the possibility of a philosophical theory of discovery, but for the above listed and refuted arguments, have been by and large dogmatic and cavalier.

Secondly, such a theory must not try to be a logic or even a set of logics of discovery in the sense of a bunch of algorithms and formal rules that constitute thumb-rules for discovery, whether those rules are inductive as inductivists thought and non-inductive as non-inductivists thought. Apart from the fact that an attempt to provide a theory of discovery in terms of algorithms is bound to fail miserably, such an attempt fails to do justice to creativity that is involved in discovery and the specificity of a particular discovery. A philosophical theory of discovery should attempt to be a methodology of discovery rather than a logic of discovery.

Thirdly, it must reject the traditional dichotomy between discovery and justification such that a philosophy of discovery should not be construed as an appendage to the existing philosophy of justification. In other words, the spirit of the attempt must be to view the totality of the scientific activity. It may be that within the totality one might make certain distinctions of stages, but these distinctions are to be made in heuristic and not in temporal or logical terms. The question whether discovery should be viewed in the narrow sense of what precedes testing or in the comprehensive sense of covering the totality of all the contexts through which an idea passes cannot be settled so easily. The first alternative does not radically depart from the traditional dogma of the exclusive logicality of the context of justification. It overlooks the fact that the traditional view did not just blind us to one dimension of scientific enterprise viz., what precedes testing but distorted the overall picture of science. On the other hand, the second sense of 'discovery' does not do justice to the specificity of the different contexts that figure in the life of an idea. Perhaps a viable alternative is to first start with taking into account all that precedes justification and then point out its ramifications in the subsequent contexts. However, it must be admitted that this is more easily said than done. The main difficulty lies in the very complexity of the semantic content of the concept of discovery. As McMullin [25], p. 328 rightly points out:

"The term 'Discovery',... conveys the suggestion that a positive appraisal has been made conveys the suggestion that a positive appraisal has been made. One does not ordinarily speak of a new theory as a 'discovery' until it has proved itself in some way. A conjecture, no matter how ingenious, does not qualify as a 'discovery' as that term is most often used by scientists"

However, according to him, discovery

"as the initial creative formulation, the shaping of a conjecture, the apt conceptual modification, prior to the question of explicit assessment. ...does it belong to the realm of rationality; in some sense it can be said to be central to it. For the creative ability to shape a 'likely story' makes far more of a demand on rational powers than does the mere ability to follow the rule-bound steps of deduction" [24], pp. 28-29

All this shows, as McMullin [25], p. 30 rightly concludes, "A Discovery... is a unique and complex human event, not just an abstract statement". 
The complexity of the texture of discovery can be gauged by the fact that philosophers of science have been continuously increasing the number of contexts into which scientific thought-process is divided. Positivists, Popper [20] and even Hanson [26], see two contexts, namely, that of discovery and justification. Rudner [27] added validation as distinct from justification. Lary Laudan [28] sees three, namely, those of generation, pursuit, and justification. Burian adds preparation stage distinct from generation. Finacchiaro adds a clarification and understanding stage independent of justification or acceptance. Taking all these into consideration we have six contexts or so into which scientific thought process is divided. The word 'discovery' might apply to one or two or the totality of all the contexts equally well. This systematic ambiguity puts into question the neat and clean construal of scientific thought-process. Hence, it immediately follows that an adequate philosophical theory of discovery must not consider 'theory' as the irreducible unit of scientific thought, but view theory within the wider context characterized by problem, constraints, etc. As we have previously seen that a philosophical theory of discovery cannot be a logic of discovery. This point is reinforced by the fact that from the point of view of the problem of discovery theories, the abstract statements cannot be considered to be irreducible and autonomous units of scientific thinking. From this it does not follow that a philosophical theory of discovery is a psychological theory of discovery. For the ideas of problems and constraints, which should inform our understanding of discovery, are not psychological concepts and therefore discovery is not a mere psychological phenomenon.

The fact that a discovery is a unique and complex human event compels us to characterize a philosophical theory of discovery as a theory of understanding in hermeneutical sense rather than an explanatory theory.

Apart from the indeterminateness of discovery in the scheme of scientific thought to which I have just now referred, "discovery" displays heterogeneity of application in that we can speak of discovery of facts, theories, laws, entities, principles and a host of such semantic and nonsemantic creatures. Whether those multifarious applications have something in common or have only family resemblance is in itself an interesting question.

However, there is a further problem concerning whether 'discovery' is a process-word or an achievement-word or something in between. If it is taken as an achievement-word, then few scientific discoveries would be discoveries in the real sense of the term, and if it is taken in the process sense everything in science becomes discovery. Neither of the two horns of the dilemma is acceptable. Hence, the need for something in between such that the word 'discovery' becomes an achievement-word though what is achieved may not be infallible. In this weaker sense 'discovery' implies meeting of certain constraints. They may be constraints or norms, which decide whether or not an idea is worth a second look; or slightly more strongly, they may be constraints that decide whether or not an idea is accepted and certified. Both the senses of discovery are important. What is common to them is the fact that they are normative. Hence, discovery is not merely a descriptive word. Undoubtedly, we have done some violence to the word by not confining it to achievement- sense. This is inevitable in doing justice to the multifaceted and multifarious dimensions of the phenomenon denoted by 'scientific discovery.'

\section{REFERENCES}

[1] Nickles, T. (Ed.) (1980). Scientific Discovery, Logic and Rationality. Dordrecht: Reidel.

[2] Nickles, T. (1994). "Enlightenment Versus Romantic Models of Creativity in Science--and Beyond," Creativity Research Journal, 7:277-314

[3] Schunn, C. D. \& Dunbar, K. (1996). "Priming, Analogy, and Awareness in Complex Reasoning," Memory \& Cognition24:271-284.

[4] Howard, D., 2006, "Lost Wanderers in the Forest of Knowledge: Some Thoughts on the Discovery-Justification Distinction", in J. Schickore and F. Steinle (ed.), Revisiting Discovery and Justification. Historica and Philosophical Perspectives on the Context Distinction, Dordrecht: Springer, 3-22.

[5] Faye, Jan, 2014, The Nature of Scientific Thinking: On Interpretation, Explanation, and Understanding, London: Palgrave Macmillan.

[6] Amsterdamski, Stefan: 1975, Between Experience and Metaphysics, Dordrecht, Holland: D. Reidel, pp. 53-54.

[7] Schaffner, K. (1993). Discovery and Explanation in Biology and Medicine. Chicago: University of Chicago Press.

[8] Klahr, David and Herbert A. Simon., 1999, "Studies of Scientific Discovery: Complementary Approaches and Convergent Findings", Psychological Bulletin, Vol. 125, No. 5 ,524-543.

[9] Thagard, P., (2012), The Cognitive Science of Science, Cambridge, MA: MIT Press.

[10] Carnap, Rudolf: 1962, Logical Foundation of Probability, Chicago: University of Chicago Press.

[11] Hempel, Carl G.: 1966, Philosophy of Natural Science, Englewood Cliffs, New Jersey: Prentice-Hall.

[12] Peitruska-Madej, Elzbieta: June, 1985, 'Should Philosophers of Science Consider Scientific Discovery?’ Ratio, XXVII, No.1, P 11-13.

[13] Monod Jacques, 1983, Chance and Necessity, Glassgow: Colins/Fount Paperback.

[14] Hesse, Mary B., 1958-9, 'Theories, Dictionaries and Observation', British Journal for the Philosophy of Science, IX, and also, 'The Explanatory Function of Metaphor', in Y.bar-Hillel (ed.), Logic Methodology and Philosophy of Science, Amsterdam: North-Holland, 1965.

[15] Flew, Anthon: 1965, 'Induction and Standards of Rationality', in Pap and Edwards (ed.), Introduction to Modern Philosophy, New York: Free Press, p. 160.

[16] Mill, J.S. 1843, A System of Logic Ratiocinative and Inductive, Being a Connected View of the Principles of Evidence and The Methods of Scientific Investigation, London: Parker, Son and Bowin.

[17] Kuhn, Thomas S.: 1977, The Essential Tension, Chicago: Univ. of Chicago Press, p. 16.

[18] Hesse, Mary B. 1965, 'The Explanatory Function of Metaphor', in Y. Bar-Hillel (ed.)., Logic, Methodology and Philosophy of Science, Amsterdam: North-Holland.

[19] Curd, Martin V. 1980, 'The Logic of Discovery: An Analysis of Three Approaches' in T. Nickles (ed.), Scientific Discovery, Logic and Rationality, Dordrecht, Holland: D. Reidel.

[20] Reichenbach, Hans: 1938, Experience and Prediction, Chicago: Univ. of Chicago Press.

[21] Popper, Karl R.: 1959, The Logic of Scientific Discovery, New York: Basic Books, pp. 31-32.

[22] Sudhakar V. 1993, 'Problems and Constriants in Thomas Nickles's Theory, Philosophy and Social Action, Vol. 19, No. 4. pp. 19-24.

[23] Nickles, Thomas, 1980, 'Introductory Essay: Scientific Discovery and the Future of Philosophy of Science' in T.Nickles (ed.), Scientific Discovery, Logic and Rationality, (henceforth SDLR), Dordrecht, Holland: D. Reidel, p. 2\&35.

[24] Burian, Richard M.: 1980, 'Why Philosophers Should Not Despair of Understanding Scientific Discovery', in T. Nickles (ed.), Scientific Discovery, Logic and Rationality, Dordrecht, Holland: D. Reidel, p. 328.

[25] McMullin, Erran: 1980, Panel Discussion on "The Rational Explanation of Historical Discoveries': in T. Nickles (ed.), Scientific Discovery, Logic and Rationality, Dordrecht, Holland: D. Reidel, p. $28-30 \& 328$.

[26] Hanson, Norwood Russell: 1981, Patterns of Discovery, Cambridge: Cambridge University Press.

[27] Rudner, R., 1953, "The Scientist Qua Scientist Makes Value Judgments", Philosophy of Science, 20: 1-6. 
[28] Laudan, Larry: 1977, 'The Sources of Modern Methodology' in R.E. Butts and J. Hintikka (eds.), Historical and Philosophical Dimensions of Logic, Methodology and Philosophy of Science, Dordrecht, Holland: D. Reidel.

[29] Vyaltsev, Anatoli: 1985. 'The Definition of Scientific Discovery,' in The History of Science: Soviet Research, Vol.II, Moscow: USSR Academy of Science. 